\title{
EXTRACTIVISMO, DERECHO Y CONFLICTO SOCIAL EN COLOMBIA*
}

\section{Extractivism, law and social conflict in Colombia}

Henry Bocanegra Acosta**, Jorge Enrique Carvajal Martínez ${ }^{* * *}$

Recepción: 18/9/18.. Aceptación: 10/01/19

DOI: http://dx.doi.org/10.21017/Rev.Repub.2019.v26.a63

\section{RESUMEN}

El presente artículo es resultado del proyecto de investigación titulado Derecho, políticas públicas y movimientos sociales. La investigación tiene como objetivo presentar la manera como se han desarrollado las consultas populares en Colombia frente a los procesos de extracción y evidenciar como este mecanismo de participación se ha convertido en el medio para la defensa del medio ambiente y la lucha de las comunidades en contra del modelo de minería extractiva en Colombia. La pregunta problema de investigación es ¿Cómo en Colombia las consultas populares garantizadas en la Constitución Política y el ordenamiento legal vienen siendo utilizadas por la sociedad para cuestionar el modelo extractivo? Es una investigación desarrollada desde un enfoque socio jurídico, en la medida que confronta un hecho social frente a un elemento normativo de participación ciudadana; su enfoque es cualitativo y las herramientas de investigación es de análisis documental. La conclusión es que las consultas

* Artículo resultado de investigación y de cohesión del proyecto titulado Derecho, políticas públicas y movimientos sociales, Grupo de Investigaciones Socio Jurídicas -GISJ.

** Doctor en Sociología Jurídica e Instituciones Políticas, de la Universidad Externado de Colombia. Especialista y magíster en Administración Pública, Escuela Superior de Administración Pública (ESAP). Magíster en Educación de la Universidad Antonio Nariño. Abogado de la Universidad Libre. Licenciado en Ciencias de la Educación -especialidad sociales-. Docente investigador de la Universidad Libre, Grupo de Investigaciones Socio Jurídicas (GISJ); docente de la Corporación Universitaria Republicana. Investigador Asociado Colciencias. Identificador ORCID: https://orcid.org/0000-0001-7623-7483.

*** Doctor en Sociología Jurídica e Instituciones Políticas, tesis con mención de reconocimiento, Universidad Externado de Colombia. Magíster en Estudios Políticos del Instituto de Estudios Políticos y Relaciones Internacionales IEPRI de la Universidad Nacional. Especialista en sociología jurídica, Universidad Externado de Colombia. Abogado, Universidad Nacional de Colombia y Licenciado en Ciencias Sociales, Universidad Distrital Francisco José de Caldas. Profesor Asociado de la Facultad de Derecho de la Universidad Nacional de Colombia. Investigador sénior Colciencias. Identificador ORCID: https: / / orcid.org/0002-4478-3575. 
populares utilizadas por la sociedad en el marco del conflicto minero energético han sido importantes en la medida que las comunidades afectadas por el modelo extractivista pueden ejercer su derecho a decidir la conveniencia o no de dicho modelo. Las consultas populares sirvieron como herramientas novedosas y eficaces; sin embargo, en Colombia las altas cortes han venido limitando la eficacia de estas acciones constitucionales.

Palabras clave: minería, extractivismo, democracia, derecho de autodeterminación.

\begin{abstract}
This research article is the result of research on the project entitled, Public Policy, Law and Social Movements. The objective of this research is to present how popular consultations have been developed in Colombia regarding extraction processes. This is to demonstrate how this participation mechanism has become a tool for environmental advocacy and the fight of communities against the extractive model. The research question is how popular consultations are being used by Colombian society so as to question the extractive model? The research method tackles a socio-legal field as it confronts a social fact against a normative element of citizen participation, its approach is qualitative and the research tools stem from the documentary analysis. The article concludes that popular consultations in the context of the mining energy conflict have been important insofar as the communities affected by the extractivist model might exercise their right to decide whether or not to implement the energy mining model. The above-mentioned tools were innovative and effective; however, Colombian high courts have curtailed the effectiveness of these constitutional actions.
\end{abstract}

Keywords: mining, extractivism, democracy, right of self-determination.

\title{
INTRODUCCIÓN
}

El modelo económico neoliberal impone una nueva división mundial del trabajo que se pretende presentar como una tendencia de la globalización de la producción, realidad que naturalmente favorece a las empresas trasnacionales, le otorga un protuberante protagonismo al sistema financiero internacional y obliga una apertura de los mercados nacionales. Es decir, la humanidad enfrenta un modelo que ha sido obligado a escala global por las entidades multilaterales de crédito, el capital financiero internacional, por los países desarrollados: Estados Unidos, Alemania, Inglaterra, Francia y Japón, entre otros. Los efectos para los países atrasados y dependientes y las políticas económicas nacionales son diversos dependiendo del grado de negociación que pueden 
ejercer frente al mundo desarrollado. Sin embargo, la tendencia a estado dirigida a imponer una serie de políticas que trastocan sus ordenamientos jurídicos, los alcances político sociales del mismo Estado y de la gestión y la inversión públicas. En este sentido, las políticas monetaria y fiscal están orientadas a la disminución de la inflación y la deuda pública, la privatización de las empresas estatales, la desregulación estatal en asuntos económicos, la apertura de las economías a los mercados globales, todo en la perspectiva de dar prioridad a la exportación de productos y la adecuación de estos a los precios internacionales (Santos, 2003, págs. 170-173).

Gran parte de los países subdesarrollados se ha insertado al modelo neoliberal por medio de la exportación de productos anclados en el sector primario de la economía, cuya actividad productiva se caracteriza por la extracción de materias primas, especialmente en el sector minero energético, la explotación forestal, la agricultura y la ganadería. En el espectro minero energético a nivel mundial se presenta una disminución de los precios de estos productos, lo que a su vez genera una sobre explotación de estos bienes por parte de las transnacionales generado, con ello, un mayor daño a los ecosistemas. Este modelo ha sido altamente cuestionado por diversos sectores sociales, académicos e investigadores en diversos países de la región, por los graves daños ambientales que ocasiona, el aumento de los niveles de contaminación y la pérdida de recursos hídricos, faunísticos y forestales. Para el caso de América Latina el modelo extractivista basado en la minería ha incrementado los Conflictos socioambientales como nunca antes (OCMAL, Observatorio de Conflicto Mineros de América Latina, 2017).

En América Latina el modelo de explotación minero energético ha planteado desafíos a las comunidades y organizaciones sociales: unos concernientes con el estudio de la realidad socioambiental, política y legal sobre la que se hace necesario actuar; desafíos relacionados con los procesos organizativos y de unidad de acción de diferentes iniciativas, sectores socioeconómicos y fuerzas políticas interesadas en el asunto y sobre las transformaciones sociales y políticas que se hace necesario plantear; otros con la definición de las acciones legales o de movilización adecuadas a unas condiciones para su ejercicio, considerando el nivel y la correlación de fuerzas existentes y posibilidades de éxito. En la región andina se han presentado alternativas políticas que cuestionan este modelo de crecimiento, por ejemplo, las acaecidas con las transformaciones constitucionales de Bolivia y Ecuador que introducen propuestas sociales desde la interculturalidad y plurinacionalidad, así como nuevos modelos de desarrollo económico respetuosos con las aspiraciones sociales y el medio ambiente, procesos denominados como constitucionalismo transformador (Santos \& Exeni, 2012). Otra manera de cuestionar el extractivismo minero energético es la acción social colectiva representada en diversas formas de 
protesta social y de movimientos antiextractivistas, los cuales cuentan en su repertorio con diversas formas de acción social (Martínez, 2018). En este escenario de movilización, los mecanismos jurídicos, particularmente los que emergen del neoconstitucionalismo contemporáneo, se han convertido en referentes útiles para enfrentar el susodicho modelo.

«En el caso colombiano, diferentes eventos buscaron favorecer la actividad extractivista en este período. Particularmente, la inversión canadiense en Colombia fue una de las que más fijaron su atención en el sector extractivo, lo que a su vez elevó sustancialmente la exploración y extracción de minerales y petróleo, al tiempo que se incrementaron las disputas y conflictos. Con la caída de los precios internacionales del petróleo y carbón, desde agosto de 2014, el post consenso de los 'commodities' desnudó la volatilidad de la actividad, así como las consecuencias y efectos negativos del modelo implementado» (Rodríguez, Frasser \& Andapiña, 2017, p. 2).

El objetivo de este trabajo de investigación es evidenciar cómo en Colombia la herramienta jurídica de la consulta es usada por las comunidades como mecanismo de acción social para la defensa del territorio frente al modelo extractivista.

El neoconstitucionalismo contemporáneo, generado con posterioridad a la Segunda Guerra Mundial, ha permitido entender los derechos humanos como un mecanismo de acción política y una gramática desde la cual los ciudadanos y los movimientos sociales interpretan sus realidades y necesidades, escriben sus aspiraciones y construyen propuestas de transformación y reivindicación social. Esta situación para América Latina se intensificó con los procesos de transiciones a la democracia acaecidos en las dos últimas décadas del siglo XX (Carvajal, 2012).

En Colombia se evidencia que el uso de las consultas populares, mecanismo incorporado al ordenamiento jurídico con la Constitución Política de 1991, se convirtió en una herramienta utilizada por organizaciones sociales para la defensa del territorio, del agua, del suelo y de los modelos de desarrollo alternativo contra las políticas extractivistas y los intereses de las empresas transnacionales mineras. En otros países, las organizaciones sociales también han desplegado acciones de diverso género frente a la ejecución de proyectos minero energéticos en los territorios (OCMAL, Observatorio de Conflicto Mineros de América Latina, 2017). Una importante estrategia de resistencia en la región lo constituyeron las consultas previas realizadas por comunidades indígenas. Un antecedente normativo internacional importante en lo que respecta al tratamiento en las consultas populares y la consulta previa corresponde a lo dispuesto por el Convenio 169 de 1989 de la Organización Internacional de Trabajo. 
El presente texto se organiza en tres partes: en la primera, se presenta una reflexión sobre límites del uso del derecho y las demandas sociales; en la segunda, se hace un bosquejo del significado de las consultas populares y su regulación en Colombia. Por último, se presenta el uso de las consultas en los territorios, mostrando las entidades políticoadministrativas del país en las que se han adelantado estas iniciativas y los resultados alcanzados.

\section{PLANTEAMIENTO DEL PROBLEMA}

En las dos últimas décadas del siglo XX ocurrieron varios hechos y procesos que contribuyen a trastocar el orden internacional, reconfiguran las relaciones de poder y la organización económica en un plano global, pero a su vez la exigencia del reacomodamiento y redefinición de unas nuevas relaciones de poder dentro de las sociedades nacionales: el fin de la guerra fría, la consolidación de la democracia liberal como forma de gobierno para occidente, el auge de las políticas neoliberales, pero paradójicamente también el emerger de una nueva teoría jurídica, el neoconstitucionalismo que permite un cambio, un giro del pensamiento social frente al ordenamiento jurídico. El derecho que ya no es concebido como un espacio de contradicción sino como un escenario reivindicación social; los nuevos grupos y movimientos sociales van a articular sus reivindicaciones alrededor del nuevo constitucionalismo, del derecho internacional de los derechos humanos y de instancias internacionales (Carvajal \& Guzmán, 2017a). Lo anterior generó un nuevo entendimiento de la justicia y del derecho que permite trascender el clásico escenario de los conflictos jurídicos entre particulares y se propone también para solucionar conflictos sociales.

Latinoamérica ha experimentado cambios constitucionales que reafirmaron las libertades, los derechos individuales y dieron vía a trasformación del sistema político, ampliando los mecanismos de participación política; adicionalmente, los nuevos pactos sociales incorporaron una gran gama de derechos económicos, sociales y culturales, y de otra parte, se crearon acciones constitucionales como la de tutela y la de cumplimiento, así como medios de participación política y social como la consulta previa, las acciones populares, entre otras.

El nuevo constitucionalismo ha motivado a los movimientos sociales y Organizaciones No Gubernamentales a utilizar las acciones constitucionales y los medios de participación para la solución de los conflictos sociales y revertir políticas públicas o decisiones económicas que afectan el habitad y los ecosistemas. En esta relación el problema de investigación que se propuso se sintetiza a través de un interrogante: ¿En qué medida las consultas populares establecidas en la Constitución Política y el ordenamiento legal colombiano vienen siendo utilizadas por la sociedad para cuestionar o limitar el modelo extractivo? 


\section{EL NEOCONSTITUCIONALISMO Y LOS MOVIMIENTOS SOCIALES: LA NUEVA ENCRUCIJADA.}

Con el nuevo constitucionalismo latinoamericano los grupos y movimientos sociales han usado la gramática de los derechos humanos, las acciones constitucionales y los mecanismos de participación política consagrados en las constituciones para resolver los conflictos sociales. Desde el uso de los diversos medios que otorgan las cartas políticas se ha exigido la materialización de los derechos económicos, sociales y culturales y se ha luchado por condiciones para cambiar los desequilibrios, los abusos de los poderosos y las desigualdades materiales.

Sin embargo, en este proceso se han encontrado con una encrucijada, la que imponen las políticas de estabilización y ajuste estructural, el neoliberalismo, que condiciona la realización del Estado social de derecho, debilita la capacidad de intervención social del Estado porque promueve la privatización y disminución del gasto público. Así, la construcción del Estado social queda sometida a políticas fiscales y al mandato del ejecutivo y legislativo (Pisarrelo, 2001, pág. 84 ).

Los Estados Latinoamericanos no han tenido a los derechos humanos como ejes en la construcción de las agendas públicas; que si ha estado marcada por el despliegue de unas políticas indiscriminadas de privatización de los haberes públicos y actividades de alto valor estratégico (servicios públicos domiciliarios, comunicaciones, salud, educación) y la reprimarización de la economía basada en lógicas extractivistas. La reducción del Estado ha afectado actividades de un valor social, caso de los servicios públicos, la minimización de un garantismo laboral arduamente construido a lo largo del siglo y en general de la pauperización del Estado en cuanto fuerza social productiva, como motor del progreso y el bienestar colectivo. Lo que ha predominado han sido unas políticas públicas que privilegian el asistencialismo focalizado y la implantación de un esquema de apropiación de la riqueza social, cuya fuente principal deviene de la economía extractiva; quienes quedan excluidos del modelo resultan estigmatizados como grupos «no normales», culpables de su propia exclusión (Pisarrelo, 2001, pág. 89). Adicionalmente, de los efectos del extractivismo sobre el ambiente, como generador de nuevos conflictos sociales y formas violentas y gansteriles de acumulación de capital.

En el contexto de avance de las políticas de corte neoliberal se consolida un nuevo orden global, los países en vías de desarrollo no pasan de jugar un papel subordinado en el plano económico, el de proveedores de materias primas a las empresas transnacionales. Es decir, el mundo, la región y el país enfrentan un modelo que se impone sin consideración alguna por las 
demandas, las necesidades, las aspiraciones y los anhelos de los trabajadores, clases medias, intelectuales, grupos y movimientos sociales; sus reflexiones o propuestas se tienden a desconocerse, a invisibilizar a la hora de definir el rumbo de las políticas públicas. Es la banca multilateral la que tiene un papel sustancial y definitorio en el rumbo de la política económica y del modelo de desarrollo que deben seguir los países atrasados (Carvajal \& Guzmán, 2017).

Ante esta realidad y a pesar del relativo auge de la doctrina neoliberal, los movimientos, grupos sociales y organizaciones políticas alternativas han desplegado, en todo el continente, un claro accionar reivindicativo desde el derecho; de manera pragmática se hace uso de las acciones constitucionales y los mecanismos de participación política que en alguna medida legitiman las propias reclamaciones y los enaltece como actores políticos que promueven las condiciones para un real ejercicio de los derechos, la superación de los desequilibrios y las desigualdades materiales generadas por el modelo económico y por un acumulado de conflictos sociales y desatinos institucionales y democráticos no superados.

Para hacer realidad el Estado constitucional y democrático de derecho, los movimientos y grupos sociales han desarrollado una estrategia de exigibilidad de los derechos que conjuga elementos de solidaridad, de deliberación y de acción. Los derechos humanos deben comprenderse no como una concesión paternalista del Estado programada por la burocracia estatal, sino que para el propio Estado es su razón de ser, el fundamento desde el cual se le da sentido a la gestión pública y se logra la materialización del Estado Constitucional en armonía con el derecho internacional de los derechos humanos.

El uso de las acciones y mecanismos de participación consagrados en la Constitución tiene dos aristas: por un lado, puede contribuir a satisfacer demandas sociales encaminadas a la exigibilidad de los derechos humanos; por otro, se puede convertir en un escenario de frustración en la medida que puede limitar los derechos. A continuación, presentamos las consultas populares, uno de los mecanismos de participación ciudadana utilizados por organizaciones sociales para la defensa de los derechos ambientales frente a la explotación minero energética; el propósito, como lo planteamos anteriormente, es poder avanzar en la respuesta al problema jurídico de investigación.

\section{LAS CONSULTAS POPULARES EN EL ORDENAMIENTO JURÍDICO COLOMBIANO}

Las consultas populares se encuentran consagradas ampliamente en la legislación colombiana. El artículo 113 de la Constitución Política se refiere a los mecanismos de participación de la ciudadanía como un ejercicio de soberanía; 
estos son el voto, el plebiscito, el referendo, la consulta popular, el cabildo abierto, la iniciativa legislativa y la revocatoria del mandato (Constitución Política de 1991. Artículo 103).

El artículo 105 de la Constitución se refiere específicamente a las consultas populares de la siguiente manera:

«Previo cumplimiento de los requisitos y formalidades que señale el estatuto general de la organización territorial y en los casos que este determine, los Gobernadores y Alcaldes según el caso, podrán realizar consultas populares para decidir sobre asuntos de competencia del respectivo departamento o municipio». (Constitución Política de 1991, artículo 103)

Inicialmente, y por mandato constitucional, las consultas populares solo se pueden adelantar por iniciativa de los Gobernadores y Alcaldes, dejando en un segundo plano a las iniciativas ciudadanas frente a los asuntos de competencia local.

Además, la Ley 134 de 1994 reglamentó los mecanismos de participación ciudadana, este ordenamiento indicó que la consulta popular es una herramienta que tiene como propósito someter a decisión de la sociedad una pregunta de carácter general sobre un asunto de trascendencia nacional, departamental, municipal, distrital o local. Esta pregunta es presentada por las autoridades territoriales de orden nacional (el presidente), departamental (el gobernador) o municipal (el alcalde).

El artículo 56 de la Ley 134 del 94 se refiere a los efectos de la consulta e indica que la decisión que haya tomado el pueblo es de obligatorio cumplimiento por parte de las autoridades correspondientes y se deberán adoptar las medidas necesarias para hacerla efectiva ya sea mediante la expedición de una Ley, una ordenanza, un acuerdo o una resolución local (Ley 134 de 1994, artículo 56).

Por otra parte, en el marco normativo vigente se encuentra la Ley 136 de 1994 o denominada Ley Municipal que en el artículo 33 establecía que para el desarrollo de proyectos que amenacen con crear un cambio significativo en el uso del suelo, que dé lugar a una transformación de las actividades tradicionales del municipio como los proyectos relacionados con naturaleza turística, minería u otro tipo se deberá realizar una consulta popular (Ley 136 de 1994, artículo 33). De todos modos, es preciso señalar que este artículo que obró como un adecuado instrumento de institucionalización de los conflictos sociales, de garantía para la participación ciudadana en asuntos de interés colectivo en el ámbito local, fue declarado inexequible por la Corte Constitucional en Senten- 
cia C-053 de 2019, en una decisión soportada en varios juicios jurídicos, uno de ellos: fue tramitada como ley ordinaria y su tema general se refería a la adopción de normas tendientes a modernizar la organización y el funcionamiento de los municipios. No obstante, en transgresión del artículo 105 superior reguló una materia propia de la ley orgánica (Corte Constitucional en Sentencia C053 de 2019). Sobre este tema volveremos más adelante.

Hasta el 2015 los únicos facultados para promover las consultas populares eran las autoridades, ya fuese el presidente, el gobernador o el alcalde. Pero con la expedición de la Ley 1757 de 2015 se estableció que se podrían adelantar consultas populares a iniciativa de la ciudadanía. El capítulo de las reglas comunes a los mecanismos de participación ciudadana estableció que cualquier ciudadano, organización social, partido o movimiento político podrá promover una consulta popular de origen ciudadano (Ley 1757 de 2015, artículo 5).

La consulta popular, como cualquier otro medio de participación que promueve el ejercicio democrático, se encuentra sometido a una serie de requisitos. El ordenamiento legal señala que para que una consulta popular sea válida es indispensable la participación de una tercera parte del censo electoral (33 por ciento), y para la adopción de la decisión se necesita la mitad más uno de los sufragios válidos (Ley 1757 de 2015, artículo 41). De la misma manera, establece que las consultas populares que provengan de ciudadanía en las entidades territoriales requieren del apoyo de un número no menor del 10\% de ciudadanos que hagan parte del censo (Ley 1757 de 2015, artículo 9).

La reglamentación de las consultas populares no se ha dado únicamente por la vía legal. El Consejo de Estado y la Corte Constitucional se han referido en diferente jurisprudencia a este tema. La Corte Constitucional en la sentencia T-445 de 2016 definió las consultas populares de la siguiente manera:

«Una Consulta Popular es, ante todo, una manifestación de voluntad políti$\mathrm{ca}$, que posteriormente, y de manera diferida e independiente produce una norma jurídica, la cual, puede ser objeto de control judicial a través de los mecanismos judiciales de control de actos administrativos o de leyes de la República. Teniendo en cuenta dicha situación, esta Corporación considera necesario precisar, que los tribunales administrativos deben en la medida de lo posible limitarse a ejercer el control constitucional de la manera más garantista posible al derecho a la participación ciudadana (formalparticipativo). Asunto distinto, será el control constitucional que una vez finalizado el proceso político se puede efectuar al texto, ordenanza o acuerdo que se derive de la realización de dicho mecanismo de participación ciudadana» (Corte Constitucional. Sentencia T-445/16). 
La Corte Constitucional también expidió la Sentencia C-273 de 2016, mediante la cual se declaró la inexequibilidad del artículo 37 del Código de Minas, el cual limitaba las competencias de los municipios (Corte Constitucional. Sentencia C-273 de 2016).

«Artículo 37. Prohibición legal. Con excepción de las facultades de las autoridades nacionales y regionales que se señalan en los artículos 34 y 35 anteriores, ninguna autoridad regional, seccional o local podrá establecer zonas del territorio que queden permanente o transitoriamente excluidas de la minería. Esta prohibición comprende los planes de ordenamiento territorial de que trata el siguiente artículo» (Corte Constitucional. Sentencia C-273/16).

La inexequibilidad del artículo 37 del Código de Minas fue un logro importante ya que permitió que la regulación del uso de los suelos que quedasen en cabeza de los municipios, frente a proyecto minero-energéticos. En este contexto legal, se presentó un número importante de acciones populares que tenían como conflicto la defensa del territorio frente al modelo extractivista.

\section{LAS ACCIONES POPULARES, DEFENSA DEL TERRITORIO Y LUCHA CONTRA EL EXTRACTIVISMO MINERO ENERGÉTICO}

Antes de entrar en detalle sobre las consultas populares en lo local, es importante tener claridad frente a los elementos que se trabajan desde la autoridad para definir cuándo un proceso es minero energético. Actualmente, en Colombia existen dos figuras de extracción minera las cuales se encuentran divididas temporalmente. En primer lugar, esta la etapa que tiene que ver con los contratos de aporte minero los cuales se encuentran regulados por el Código de Minas, regulación que abarca el periodo de 1988 hasta 1998, y en la segunda etapa se habla de contratos de concesión regulados en el nuevo código de minas del año 2001. Se puede afirmar que a partir de este nuevo ordenamiento legal Colombia se enmarcó en el modelo neoliberal extractivista estimulando las iniciativas minero energéticas, con la promulgación del nuevo código de minas; Colombia experimento un auge inusitado en la expedición de licencias de exploración y explotación; se calcula que aproximadamente hay 5,6 millones de hectáreas de tierra destinadas para la explotación minero-energética (Grupo Semillas, 2017). Figura 1.

En Colombia a partir del 2001, los diversos gobiernos han realizado lo que denominan ruedas de negocios por un período de 5 años para ofertar cerca de 2,9 millones de hectáreas de tierras donde hay certeza de la existencia de depósitos mineros (áreas tipo 1; estas se encuentran subrayadas de color verde en el mapa 1). Igualmente, ha ofertado alrededor de 17,6 millones de hectá- 


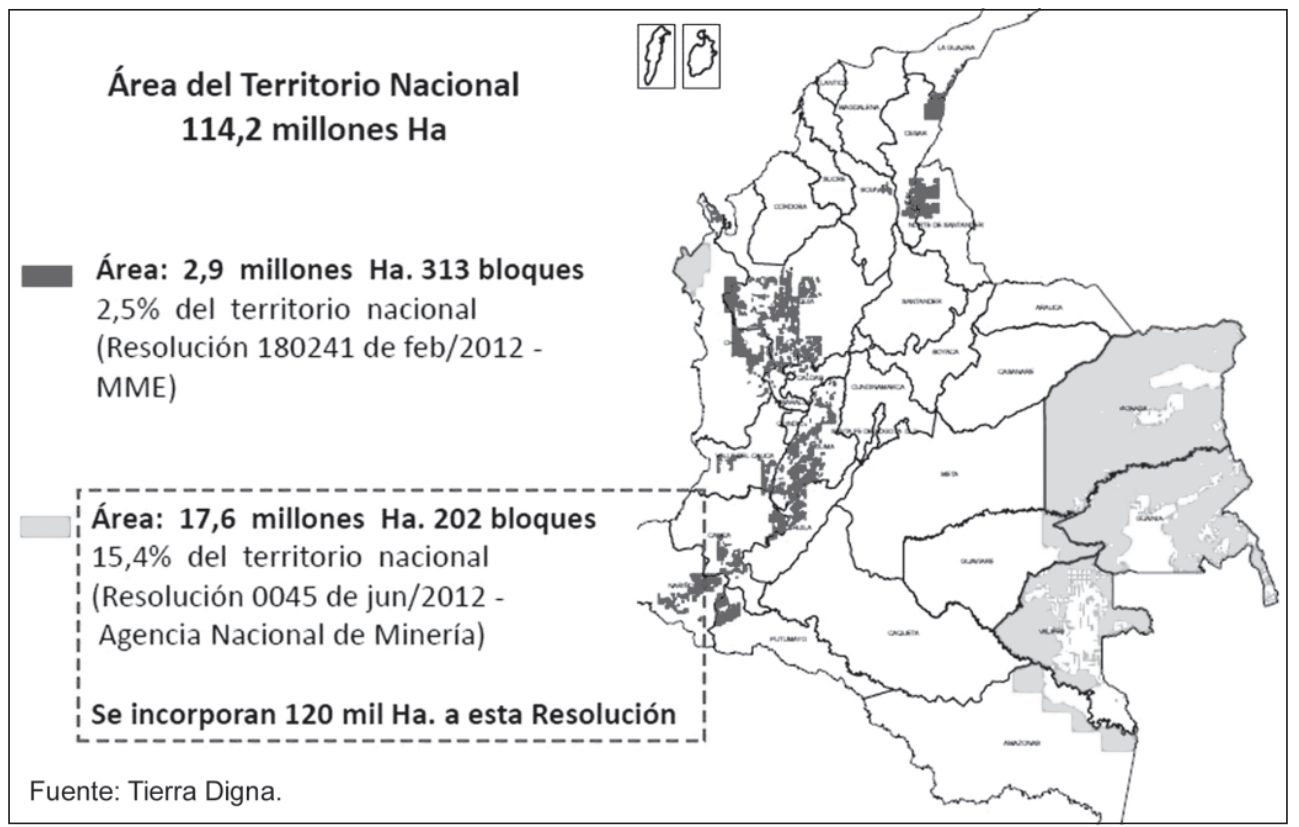

Figura 1. Cuadro obtenido de Tierra Digna ${ }^{1}$. Citada por Grupo Semillas 2017.

reas en un plazo de 10 años, áreas que requiere mayor información sobre sus depósitos mineros (áreas tipo 2, estas se encuentran coloreadas de amarillo en el mapa 1). En esta modalidad el Gobierno Nacional solo se preocupa por otorgar áreas de alto contenido estratégico para su explotación y de esta manera obtener beneficios económicos, dejando en segundo plano criterios ambientales, poblacionales y sociales (Grupo Semillas, 2017).

Lo que se evidencia de estas concesiones es la falta de concertación entre el gobierno nacional y los gobiernos locales para establecer la conveniencia y la aceptación de las comunidades de este modelo de producción y de uso del suelo y subsuelo en sus territorios. Las consultas populares se han convertido en un recurso de las comunidades locales para confrontar la política extractivista, visibilizar sus reivindicaciones, ganar interlocución ante las autoridades nacionales y el empresariado minero, en un contexto de persecución de la lucha social por el derecho al ambiente sano, de estigmatización y auge de los asesinatos contra líderes sociales y ambientalistas, con una manifiesta oposición del

1 Tierra Digna. (5 de septiembre de 2017). Áreas Estratégicas Mineras. Bogotá: Presentaciones y Relatorías - Jornadas sobre Transformaciones del Modelo Extractivo y Corporativo en Tiempos de Pos acuerdo. 
gobierno nacional y gremios de la producción a la movilización social y al usos de los mecanismos de participación ciudadana en la defensa de los territorios y para enfrentar a los sectores políticos y sociales que obran como adalides del modelo extractivista.

Las iniciativas de litigio social y jurídico en pro de un ambiente sano y contra la minería a gran escala y la explotación de hidrocarburos han sido objeto de ataques mediáticos utilizando advertencias de diverso género, entre ellas: las consultas populares y las acciones sociales de las comunidades contra la minería frenan el desarrollo del país, generan pérdidas al Estado y a las empresas. En ese sentido los pronunciamientos de la Asociación Colombiana de Minería (ACM) son claros y contundentes: «Las dificultades derivadas de la protesta social y bloqueos que el sector minero ha tenido que enfrentar, en especial desde el 2013, donde se ha evidenciado un aumento desmesurado en este tipo de eventos, con afectación a un importante número de operaciones y con altos costos económicos para las empresas y para el país (se calcula cerca de 1 billón de pesos [US\$ 357 millones] en lucro cesante 2013-2016)» (Asociación Colombiana de Minería, 2018). El presidente de esta organización gremial sectorial, Santiago Ángel Urdinola, denunciaba que: «A la fecha la industria ha mapeado 135 iniciativas municipales en contra del sector minero-energético, de las cuales unas son consultas populares y, otras, acuerdos de los concejos. De estas ya tenemos más de 50 fallos lo que ha generado un cisma jurídico, que es muy difícil de explicar a los inversionistas» (El Espectador, 12 de mayo de 2018).

Importante reconocer que los gobiernos de Álvaro Uribe Vélez (2002-2006 y 2006-2010) y de Juan Manuel Santos (2010-2014 y 2014-2018) se empecinaron en promover el sector minero energético, para el 2017 el sector aporta únicamente el 7\% del Producto Interno Bruto nacional. Si bien la mayor parte de ingresos del país proviene de la exportación de crudo de petróleo y sus derivados, estos ingresos se encuentran condicionados a diferentes factores del mercado como los bajos precios internacionales (Grupo Semillas, 2017). Según el dirigente social y líder ambientalista José Domingo Rodríguez «el problema para estas comunidades empezó en el año 2001 con la expedición de la Ley 685 llamada también Código Minero. Esta ley declara de utilidad pública e interés social la industria minera en todas sus ramas y fases» y permite, en su artículo 13, la expropiación por decreto «de bienes inmuebles y demás derechos constituidos sobre los mismos que sean necesarios para su ejercicio y eficiente desarrollo» (Comunicaciones Aliadas, 4 de junio de 2018). Complementariamente necesario citar que:

«La presión sobre la población afectada creció en el 2002 cuando el entonces presidente Álvaro Uribe Vélez (2002-2010) otorgó alrededor de 11,000 
títulos para explotación minera y de hidrocarburos, dentro de las medidas para impulsar su política de 'Confianza Inversionista'. Una investigación del 2010 de la periodista Camila Osorio para el portal La Silla Vacía afirma que 'en los ocho años que gobernó el expresidente, la superficie de hectáreas con título minero pasó de 1.13 millones a 8.53 millones. Y las hectáreas tituladas en los páramos se duplicaron con creces. Hoy en día, $6.3 \%$ de las hectáreas en los páramos $(122,000)$ están tituladas'... Esta política fue continuada a partir del 2010 por el presidente Juan Manuel Santos quien incorporó la que llamó 'locomotora mineroenergética' al Plan Nacional de Desarrollo y otorgó otros 9,500 títulos mineros». (Comunicaciones Aliadas, 4 de junio 2018).

Según datos de la Registraduría Nacional del Estado Civil (y fuentes periodísticas) en Colombia son diez (10) iniciativas de consultas populares que han llegado a votación relacionadas con actividades del sector minero energético. A continuación presentamos las consultas:

\section{Consulta 1}

Fecha: 28 de julio de 2013. Departamento del Tolima/ Municipio Piedras

Pregunta de la consulta: ¿Está de acuerdo, como habitante del municipio de Piedras, Tolima, que se realice en nuestra jurisdicción actividades de exploración, explotación, tratamiento, transformación, transporte, lavado de materiales provenientes de las actividades de explotación minera aurífera a gran escala, almacenamiento y empleo de materiales nocivos para la salud y el medio ambiente, de manera específica el cianuro y/o cualquier otra sustancia o material peligroso asociado a dichas actividades y se utilicen las aguas superficiales y subterráneas de nuestro municipio en dichos desarrollos o en cualquier otro de naturaleza similar que pueda afectar y/o limitar el abastecimiento de agua potable para el consumo humano, la vocación productiva tradicional y agrícola de nuestro municipio?

Esta primera consulta abrió la puerta a todos los municipios a preguntarse sobre la autoridad de sus habitantes en la elección sobre el uso de los suelos de sus territorios. En el municipio de Piedras estaban habilitadas un total de 5.105 personas para participar de la consulta, lo cual significaba que para alcanzar el umbral exigido de la tercera parte era necesaria la participación de por lo menos 1.702 ciudadanos. De acuerdo con el escrutinio realizado por la Registraduría se obtuvieron 3.007 votos de los cuales 2.995 votos fueron válidos. Del total de los votos válidos se registraron 2.971 votos por el «no» y 24 votos por el «sí» (Registraduría Nacional del Estado Civil, 2013). 
Los habitantes del municipio de Piedras promovieron la consulta popular debido al proyecto de La Colosa, de la empresa Anglogold Ashanti.

\section{Consulta 2}

Fecha: 15 de diciembre de 2013. Departamento del Casanare / Municipio Tauramena

Pregunta: ¿Está usted de acuerdo con que se ejecuten actividades de exploración sísmica, perforación exploratoria, producción y transporte de hidrocarburos en las veredas de San José, Monserrate Alto, Monserrate La Vega, Guafal del Caja, Bendiciones, Visinaca, Lagunitas, Aguamaco, Zambo, Oso y Jaguito, donde se ubica la zona de recarga hídrica del municipio de Tauramena?

En el 2013 los habitantes de Tauramena siguieron los pasos de los pobladores de Piedras y realizaron una nueva consulta popular. Esta consulta se realizó para preguntar si los habitantes estaban o no estaban de acuerdo con la exploración y explotación de hidrocarburos en diferentes veredas y especialmente en la zona de recarga hídrica del municipio de Tauramena.

En el municipio de Tauramena un total de 13.372 personas se encontraban habilitadas para ejercer su derecho al voto en la consulta popular. En el escrutinio realizado por la Registraduría se presentaron 4.598 votos válidos; de todos los votos válidos, 4.426 votaron por el «no» y 151 votaron por el «sí» (El Espectador, 2018).

\section{Consulta 3}

Fecha: 26 de febrero de 2017. Departamento de Cundinamarca / Municipio Cabrera

Pregunta: ¿Está usted de acuerdo que, en el municipio de Cabrera Cundinamarca, como zona de reserva campesina se ejecuten proyectos mineros y/o hidroeléctricos que transformen o afecten el uso del suelo, el agua y la vocación agropecuaria del municipio?

Los habitantes del municipio de Cabrera adelantaron la consulta popular por el interés de la empresa Emgesa para adelantar un proyector hidroeléctrico en la zona. En este municipio se encontraban habilitados para votar en la consulta 3.461 ciudadanos; de este total votaron en la consulta 1.488, de los cuales 1.465 votaron por el «no» y 23 votaron por el «sí» (El Espectador, 2018). 


\section{Consulta 4}

Fecha: 26 de marzo de 2017. Departamento de Tolima / Municipio Cajamarca

Pregunta: ¿Está usted de acuerdo que en el municipio de Cajamarca se ejecuten proyectos y actividades mineras?

El movimiento ambiental en Cajamarca inició en contra de la explotación de la Colosa por parte de la empresa Anglogold Ashanti. Del escrutinio 6.165 votos fueron por el «no» y 76 fueron por el «sí» (El Espectador, 2018).

\section{Consulta 5}

Fecha: 4 de junio de 2017. Departamento del Meta/ Municipio Cumaral

Pregunta: ¿Está usted de acuerdo ciudadano cumaraleño que dentro de la jurisdicción del municipio de Cumaral Meta, se ejecuten actividades de exploración sísmica, perforación, explotación y producción de hidrocarburos?

En esta consulta 7.475 habitantes votaron por el «no» y tan solo 183 lo hicieron por el «sí». Esta consulta es para oponerse a cualquiera exploración, perforación, explotación y producción de hidrocarburos (El Espectador, 2018).

\section{Consulta 6}

Fecha: 9 de julio de 2017. Departamento de Cundinamarca / Municipio Arbeláez

Pregunta: ¿Está usted de acuerdo sí o no con que en el municipio de Arbeláez Cundinamarca, se realicen actividades de sísmica, exploración, explotación y lavado de materiales de hidrocarburos y/o minería a gran escala?

En esta consulta los habitantes se manifestaron en las urnas en contra de la explotación de hidrocarburos y de la minería. En esta zona había dos bloques petroleros; los datos de la Registraduría mostraron que el «no» ganó con 4.312 votos y el «sí» solo obtuvo 38 .

\section{Consulta 7}

Fecha: 9 de julio de 2017. Departamento de Quindío / Municipio Pijao

Pregunta: ¿Está usted de acuerdo sí o no con que en el municipio de Pijao se desarrollen proyectos y actividades de minería de metales? 
Esta consulta se realizó sobre las actividades de minería de metales específicamente. En esta consulta 2.613 personas votaron en contra de las actividades de minería y solo 26 personas votaron a favor (El Espectador, 2018).

\section{Consulta 8}

Fecha: 17 de septiembre de 2017. Departamento de Santander/ Municipio Jesús María

Pregunta: ¿Está usted de acuerdo, sí o no, con que en la jurisdicción del municipio de Jesús María Santander, se realicen actividades de exploración y explotación minera y petrolera?

Esta consulta se realizó para frenar las actividades de exploración y explotación minera y petrolera, especialmente con la relacionado a la explotación de piedra caliza y de carbón. De las 3.259 personas habilitadas para votar, votaron 1.699. Solamente 22 personas estaban de acuerdo con la explotación y exploración mientras que 1.677 personas estaban en contra.

\section{Consulta 9}

Fecha: 1 de octubre de 2017. Departamento de Santander / Municipio Sucre

Pregunta: ¿Está usted de acuerdo sí o no que en la jurisdicción del municipio de Sucre Santander, se realicen actividades de exploración y explotación minera y petrolera?

Esta consulta iba dirigida de manera similar a la del municipio de Jesús María, querían evitar la exploración y explotación de piedra caliza y de carbón. Los datos de la Registraduría muestran que 3.016 habitantes votaron por el «no», mientras que solamente 33 votaron por el «sí» (El Espectador, 2018).

\section{Consulta 10}

Fecha: 21 de octubre de 2018. Departamento de Cundinamarca / Municipio Fusagasugá

Pregunta: ¿Está usted de acuerdo, SÍ o NO, que en el municipio de Fusagasugá se realicen actividades de exploración, perforación y producción de hidrocarburos, fracking y minería a gran escala?

Esta consulta estaba dirigida de la misma forma que en otros municipios a contrarrestar la exploración y explotación de petróleo y otros minerales. Los 
datos de los resultados son bastante elocuentes: ganó el no con un 99\% de los electores a favor de esta opción; 39.377 ciudadanos votaron y el umbral estaba en 34.846, naturalmente se cumplió con este requisito.

La consulta de Piedras Tolima marcó un hito en los procesos de resistencias contra la economía extractiva en el país. Desde esta experiencia de organización social y accionar político las consultas populares tomaron un importante impulso; los movimientos ambientalistas contaron con un instrumento institucional para reivindicar el derecho a participar en las decisiones políticas que afectan los territorios y la disponibilidad futura del agua; todo esto ha coadyuvado a la consolidación de las iniciativas, procesos y movimientos ambientalistas a pesar de las talanqueras institucionales, la violencia, la estigmatización, algunas decisiones de las Altas Cortes y la falta de implementación o aceptación de los resultados de las consultas por parte del gobierno nacional, situación que ha causado inconformidad en los municipios donde las consultas populares fueron una realidad exitosa. En este contexto se avizora un replanteamiento en el proceder táctico y del uso de los instrumentos de participación por parte de las comunidades locales frente al reconocimiento del interés colectivo por los ecosistemas y la preservación del agua para la vida.

Muchos proyectos de exploración, perforación explotación de hidrocarburos y de minería a gran escala se encuentran detenidos debido a las decisiones adoptadas en el marco de las consultas populares, pero todavía no hay decisiones definitivas en ninguna. A pesar de los aplastantes resultados en materia electoral, los movimientos ambientales han tenido que permanecer en la lucha y movilización para que los gobiernos locales y nacionales reconozcan las decisiones de los ciudadanos de los municipios que afrontan los riesgos sociales y ambientales que representan estos proyectos.

Estas son las consultas populares que han alcanzado un desarrollo mayor, en la medida que se ha realizado los respectivos procesos electorales. Adicional a estas, se han adelantado diferentes procesos donde se han inscrito los comités promotores de consultas populares a nivel local. Diferentes tribunales administrativos del país se han pronunciado sobre la constitucionalidad de las preguntas de las consultas. Mediante el estudio jurisprudencial se han podido identificar veinte sentencias que declaran la constitucionalidad de las preguntas, estas son en: 1) Piedras; 2) Cajamarca; 3) Ibagué; 4) Tauramena; 5) Monterrey; 6) La Macarena; 7) Cumaral; 8) Granada; 9) Arbeláez; 10) Cabrera; 11) Pasca; 12) Pijao; 13) Córdoba; 14) Sucre; 15) Carmen de Chucurrí; 16) El Peñón; 17) Jesús María; 18) San Lorenzo; 19) Oporapa; y 20) Mercaderes (Montenegro, 2017, pp. 61-65). De estos procesos que cuentan con sentencia de constitucionalidad favorable están suspendidas temporalmente nueve consultas 
por medidas cautelares por acciones interpuestas por las mismas empresas o el Estado Colombiano (Montenegro, 2017, pp. 61-65), esto ocurre en los municipios de Pasca, Oporapa, Carmen de Chucurí, El Peñón, Granada, Córdoba, San Lorenzo, Mercaderes y Titiribí. La consulta que debía realizarse en San Bernardo (Cundinamarca) el 21 de octubre de 2018, fue suspendida por el Consejo de Estado.

Adicionalmente, se han logrado identificar siete sentencias en las cuales se ha declarado la inconstitucionalidad de la pregunta de la consulta popular en los municipios de Pijao, en Quindío; Gachantivá, en Boyacá; Oporapa, en Huila; Pueblo Rico, en Risaralda; Cogua, en Boyacá y dos en el departamento de Antioquia. De otra parte, se encuentran en trámites previos al menos 50 procesos de consulta en diferentes municipios. Además, se tienen registros de 8 acuerdos sancionados y 21 iniciativas de acuerdos municipales (Tovar, 2017).

El siguiente mapa evidencia la ubicación de algunas de las consultas populares frente a procesos extractivos. Está claro que a pesar de que existe una mayor cantidad de procesos en departamentos estratégicos, el proceso de las consultas se ha dado en gran parte del territorio nacional (figura 2).

La consulta popular presente en el ordenamiento constitucional y legal de Colombia se constituye en una forma de participación de las comunidades locales frente a los procesos de exploración y explotación minero-energética, ante la imposibilidad de intervenir por otros medios en la respectiva toma de decisiones gubernamentales. Estos procesos participativos cada vez son más números en el territorio nacional y se han constituido como emblema de autonomía y determinación de las comunidades. La utilización de mecanismos de participación, especialmente los referidos a las consultas populares, no constituye un fin en sí mismo; estos son más bien medios que utilizan, de manera pragmática, las comunidades para proteger sus territorios y sus actividades tradicionales, entre otros propósitos.

Colombia es un país que se caracteriza por su diversidad étnica y cultural; las consultas previas, que representan un derecho fundamental para las comunidades indígenas y los demás grupos étnicos, «cuando se toman medidas (legislativas y administrativas) o cuando se vayan a realizar proyectos, obras o actividades dentro de sus territorios, buscando de esta manera proteger su integridad cultural, social y económica y garantizar el derecho a la participación» (Rodríguez, 2010, págs. 37-38), no son suficientes para proteger a esa misma diversidad; las comunidades campesinas y las comunidades en general que históricamente han desarrollado proyectos culturales, sociales y económicos no pueden quedar fuera de las decisiones frente al uso del suelo y 


\section{CONSULTAS POPULARES Y ACUERDOS MUNICIPALES PARA PROHIBIR ACTIVIDADES MINERO ENERGÉTICAS EN COLOMBIA.}

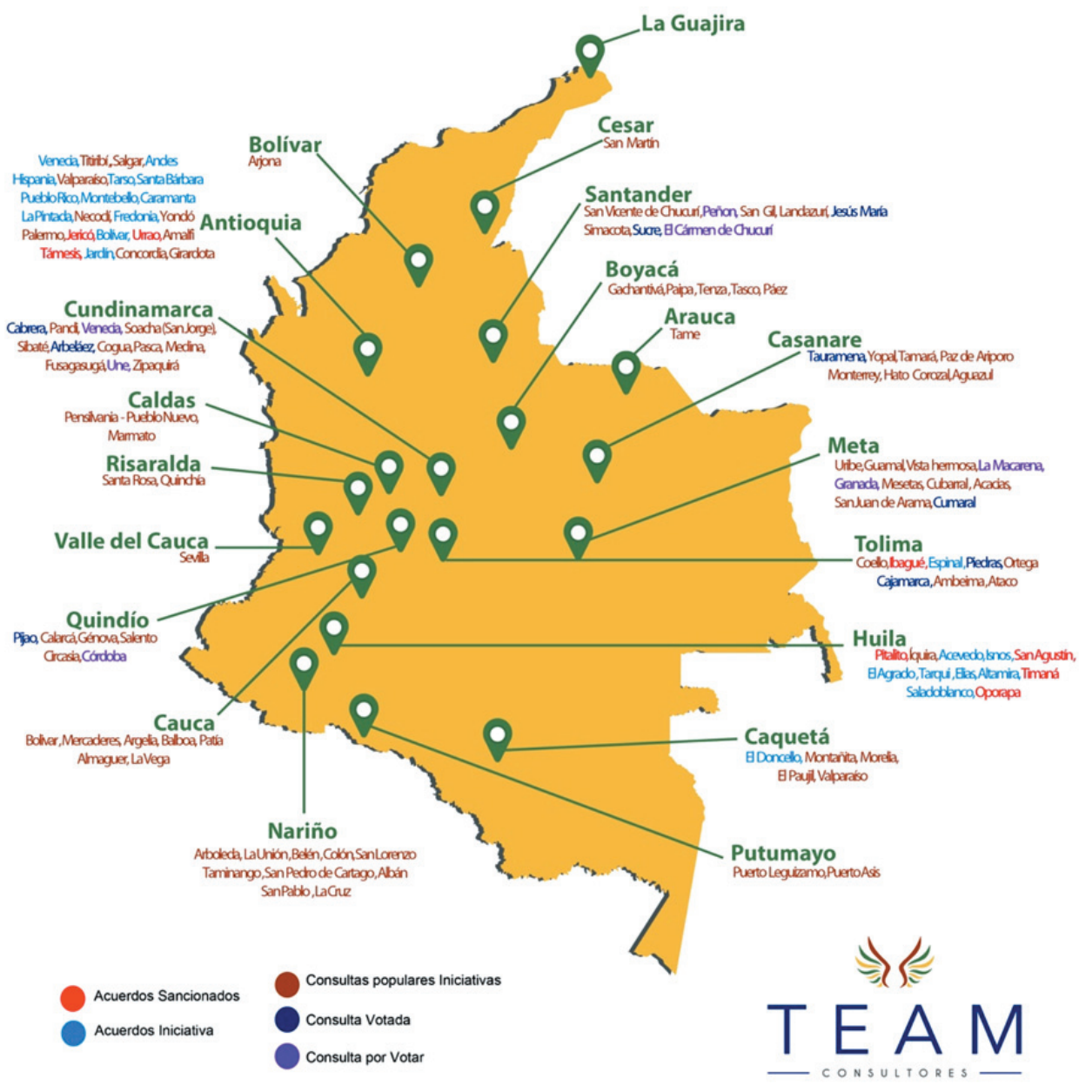

Figura 2. Mapa obtenido de «País minero» (Tovar, 2017).

frente a las consecuencias que generan los proyectos mineros energéticos en los territorios.

En Colombia, como seguramente se presenta en otras latitudes, los proyectos de explotación minero-energética, se convierten en generadores de conflictos en los diferentes ámbitos de lo social: las relaciones económicas, los patrones de consumo, la seguridad ciudadana, la cultural y las estructuras familiares; 
igualmente, los grandes proyectos minero energéticos se asocian con sistemáticas violaciones a los derechos humanos, el incremento de la violencia sociopolítica en contra de las comunidades afectadas, crisis ambiental, incremento de la desigualdad social e intervención indebida en la vida política de las comunidades y cooptación de dirigentes políticos locales (Montenegro, 2017).

En un contexto de violencia política y de utilización de formas burdas y sofisticadas de exclusión de las comunidades y sus representantes de las discusiones sobre temas sensibles y relevantes para la sociedad colombiana, persisten los asesinatos de líderes sociales y ambientalistas. Global Witness indicó que en el 2016 se presentaron en el país 200 homicidios de personas defensoras de la tierra y el medio ambiente, y desde el 2010 se han presentado casi 1.000 asesinatos y un número mucho más alto de amenazas, ataques, acoso, estigmatización y otra serie de vulneraciones a los derechos de líderes y lideresas sociales y defensores de derechos humanos (Global Witness. 2016).

En el 2016 América Latina exhibió más del 60\% de los homicidios a nivel mundial, y los países donde más se presentaron ataques contra defensores de derechos humanos y líderes sociales fueron Brasil, Nicaragua y Honduras. Pero Colombia no se queda atrás: en el 2016 se presentaron 37 casos de homicidios a defensores y defensoras de la tierra y el medio ambiente; se produjo un aumento del $40 \%$ de homicidios frente al año en el cual avanzó el proceso de paz con las FARC-EP (Global Witness, 2016).

La información mostrada por Global Witness indica claramente que se han presentado asesinatos de líderes que concretamente se oponían a proyectos minero energéticos de compañías de Canadá y Estados Unidos de América. Esto no quiere decir que la empresa haya ordenado los asesinatos, pero esta situación demuestra que las empresas no se encuentran realizando las debidas diligencias y que tendrían factores de responsabilidad por no mitigar esos riesgos (El Espectador, 2018).

En el 2017 Colombia bajó del segundo al tercer puesto en materia de asesinatos de líderes y lideresas ambientales, pero pese a esto se presentaron 24 asesinatos (Global Witness. 2017). Colombia se destaca en el concierto internacional por los altos guarismos que presenta en materia de homicidios y vulneraciones a los derechos de las defensoras y los defensores del medio ambiente y la tierra; pero igualmente otras cifras preocupan. Esta preocupación adicional se refiere exactamente a los niveles de impunidad que presenta el país respecto a estos hechos de violencia. El informe indica que desde el 2011 hasta el 2016 el grado de impunidad de los casos de violencia en contra de defensores y defensoras al medio ambiente y a la tierra es del $92 \%$. Para llegar a esta cifra se analizaron 102 casos, y la fiscalía informó que 79 se encuentran activos, dos 
archivados, dos inactivos y 19 sin certeza si están activos o no (El Espectador, 2018). Figura 3.

Estás cifras son preocupantes porque denota una clara falta de investigación rigurosa por parte de la Fiscalía General de la Nación para acopiar las pruebas e imputar a los culpables. Los autores de estos hechos violentos no responden por sus actos y las familias de las víctimas no encuentran verdad, reparación, justicia y no repetición.

\section{En Colombia reina la impunidad por muertes de líderes ambientales}

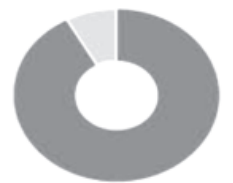

De 102 casos identificados por Global Witness entre el 2011 y el 2016, el $92 \%$ permanece en la impunidad.

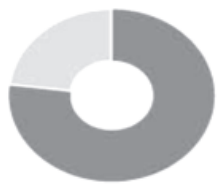

En el

$77 \%$ de los casos el autor del asesinato no se conoce.

Un ejemplo de justicia: líderes de tierras y

medio ambiente cuyos asesinos se conocen

- David Góes Rodríguez

- Eder Verbel

- Mergida Del Carmen Fuentes

- Gilmer Genaro García Ramírez

- William Castillo Chima
- Gustavo Adolfo Pizo - Pedro César García Moreno - Reinel del Jesús Cano

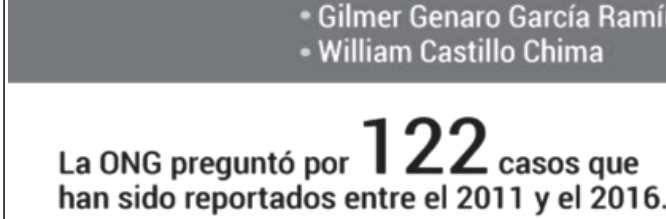

Figura 3. Cifras obtenidas de Global Witness en «El Espectador», $2018^{2}$.

2 El Espectador. "Impunidad, el capítulo colombiano de los ambientalistas asesinados". 24 de julio de 2018. Disponible en: https://colombia2020.elespectador.com/pais/impunidad-el-capitulo-colombiano-de-los-ambientalistas-asesinados 


\section{¿El Ocaso de las Consultas Populares frente al modelo extractivista?}

El 11 de octubre de 2018 la Corte Constitucional profirió sentencia unificada SU-095 de 2018 sobre consultas populares mineras en el marco de un proceso de tutela interpuesto por Mansarovar Energy Colombia Ltda, en contra del Tribunal Administrativo del Meta, que en una decisión precedente había declarado constitucional la pregunta a realizar en una consulta popular minera en el municipio de Cumaral, Meta (Ámbito Jurídico, 2018).

La Corte Constitucional analizó diferentes temas relacionados con la autonomía de las entidades territoriales en el contexto de un estado unitario. Frente a esta tensión la Corte estableció:

«La coexistencia de los principios de Estado unitario y autonomía territorial genera en su aplicación tensiones permanentes que hacen necesario en cada caso estudiar concretamente las situaciones de hecho y el uso de herramientas que permitan hacer una interpretación armónica del sistema jurídico constitucional para definir una posición frente a la aplicación de uno de estos dos principios, o de la confluencia de los mismos en caso de ser necesario. En este orden, es el mismo ordenamiento constitucional el que dispone que en estos casos para resolver las tensiones se dará aplicación a los principios de coordinación, concurrencia y subsidiariedad» (Corte Constitucional. Sentencia SU095 de 2018).

Estos principios se adecuaron a una estructura de poder centralista y excluyente, ya que los principios de coordinación, concurrencia y subsidiariedad terminan por someter el poder local a las decisiones políticas del nivel central frente a temas minero energéticos.

El Alto Tribunal indicó que las autoridades estatales competentes para otorgar títulos mineros o conceder contratos de concesión han fortalecido los espacios de participación ciudadana en la etapa contractual y pre contractual. A pesar de esto, la Corte estableció 3 puntos importantes a tener en cuenta:

- Estos mecanismos se limitan a reuniones informativas con las comunidades.

- Los resultados de las reuniones son simplemente insumos para la autoridad ambiental. Pero no son obligatorias para tener en cuenta al momento de otorgar autorizaciones ambientales.

- Los acuerdos que surjan de estas reuniones no son vinculantes (Corte Constitucional. Sentencia SU-095 de 2018). 
En el capítulo de los mecanismos de participación ciudadana expuestos en la SU-095 la Corte fue clara al indicar las reglas jurisprudenciales de la consulta popular: i) su carácter facultativo y excepcionalmente obligatorio; ii) las restricciones competenciales del pueblo y iii) la prohibición de modificar la Constitución o de desconocer derechos constitucionales (Corte Constitucional. Sentencia SU-095 de 2018).

Finalmente, la Corte ordenó al Congreso que defina las formas de participación ciudadana y los instrumentos de coordinación y concurrencia de la nación frente al territorio. Está claro que la decisión de la Corte Constitucional limitaba el poder de los ciudadanos y municipios de decidir sobre proyectos mineros y petroleros en sus territorios. Pero esta decisión de la Corte Constitucional no tendría tanta repercusión como efectivamente la tuvo la Sentencia C-053 de 2019 que declaró inexequible el artículo 33 de la Ley 136 de 1994, desde el cual se habían fundamentado todas las consultas realizadas en el país. El Alto Tribunal de lo constitucional expuso al respecto:

«La Ley 136 de 1994 fue tramitada como ley ordinaria y su tema general se refería a la adopción de normas tendientes a modernizar la organización y el funcionamiento de los municipios. No obstante, en transgresión del artículo 105 superior reguló una materia propia de la ley orgánica.

De igual manera, al establecer en cabeza de los municipios la obligación de la realización de consultas populares cuando el desarrollo de proyectos de naturaleza turística, minera o de otro tipo, amenace con crear un cambio significativo en el uso del suelo, que dé lugar a una transformación en las actividades tradicionales de un municipio, se transgrede lo dispuesto en el artículo 105 de la Constitución que consagra una posibilidad en cabeza de las autoridades municipales quienes son los llamados a decidir sobre la conveniencia y la necesidad de su realización. Una imposición de este tipo desconoce el principio de autonomía territorial consagrado en los artículos 1 y 287 de la Carta Política.

Esto mismo implica una transgresión del artículo 31 literal c de la Ley Estatutaria de Mecanismos de Participación, Ley 1757 de 2015, que dispone que las consultas populares son optativas para las autoridades territoriales. De otra parte, la Sala consideró que la norma establece de manera abierta que en cualquier tipo de proyecto es necesaria la realización de una consulta popular si genera un cambio significativo en el uso del suelo, sin consideración alguna a que en ciertos asuntos confluyen competencias no sólo locales sino también nacionales, y por tanto, que escapan del ámbito de una consulta municipal (Corte Constitucional en Sentencia C-053 de 2019).

Dentro del análisis, es necesario señalar que el artículo 33 de la Ley de 1994 se constituyó en un instrumento legal clave para ejercer el derecho a la participa- 
ción en un asunto de vital importancia para las comunidades locales. En los últimos tres lustros se posicionó como el señero mecanismo que ha logrado aquietar el crecimiento exagerado de la exploración y explotación de recursos naturales del subsuelo, en menoscabo del interés comunitario, los ecosistemas, la propensión agrícola y los valores culturales de las poblaciones en regiones o localidades con potencial minero a gran escala.

Con este cambio de jurisprudencia se podría estar entrando a una especie de limbo jurídico, según expresión que utiliza Johanna Giraldo Gómez, redactora de Ámbito Jurídico (2018), mientras el Congreso de la República pueda «crear uno o varios mecanismos de participación ciudadana e instrumentos en los que se garantice la concurrencia y coordinación entre las autoridades centrales y locales, donde se deberá tener en cuenta la 'inexistencia de un poder de veto de las entidades territoriales'» (Giraldo Gómez, Ámbito Jurídico, 2018).

De todos modos, como lo expone Giraldo Gómez, resulta interesante e importante para el país debatir el estado en que quedaron las consultas populares ya realizadas, y tener la suficiente claridad desde el ordenamiento jurídico vigente «cómo se verá afectada la autonomía territorial por la disparidad de criterios sobre el ámbito y ejercicio de sus competencias en la jurisprudencia de las altas cortes» (Giraldo Gómez, 2019). Reconociendo también que varias normas vigentes y pronunciamientos jurisprudenciales actúan a favor de la autonomía local, la participación ciudadana y la consulta popular en asuntos tan cruciales.

\section{CONCLUSIONES}

Por su carácter instrumental, la Constitución y el sistema jurídico pueden por igual satisfacer que frustrar los requerimientos de justicia y/o la lucha por una mejor sociedad a partir del reconocimiento de los derechos humanos. Las consultas populares consagradas en la Constitución Política de Colombia se concibieron como un medio de superar la exclusión política de la sociedad, así como generar nuevas formas de participación democrática para los ciudadanos. Este mecanismo tiene una gran fortaleza en la medida que se fundamenta y parte de la discusión colectiva sobre temas que tienen relación con la materialización de los derechos; para la estructura política es una oportunidad para la superación, por la vía institucional, de los conflictos políticos y sociales.

La información recogida y analizada evidencia que mecanismos como la consulta popular han sido usados por los grupos y movimientos sociales con el fin de defender la naturaleza y sus recursos frente al modelo extractivista minero 
energético vigente. Sin embargo, a pesar de que su uso venía dando resultados positivos frente a la participación ciudadana en diversos municipios de Colombia, la Corte Constitucional por medio de las Sentencias SU-095 de 2018 y C-053 de 2019 ha realizado una interpretación que restringe sustancialmente este mecanismo de participación.

Frente a la consulta popular, los órganos jurisdiccionales han variado su posición, la tendencia ha sido debilitar este mecanismo de participación política frente al modelo extractivista minero energético; los efectos de las últimas decisiones fortalecen el referido modelo y vigorizan los poderes privados y de las transnacionales cuya funcionalidad, eficiencia y rentabilidad depende de transacciones seguras y previsibles, protegidas contra los intereses colectivos de comunidades que construyen su relación con el entorno a partir de otros principios, lógicas y cosmovisiones.

\section{REFERENCIAS}

Abad, S. (2018). Colombia: Derecho a la consulta frena extracción minera. Comunicaciones Aliadas - Noticias Aliadas, 4 de junio. Disponible en: https:/ / www.comu nicacionesaliadas.com/colombia-derecho-a-la-consulta-frena-extraccion-minera/

Ámbito Jurídico. «Importante: Corte publica sentencia de unificación sobre consultas populares mineras». 21 de noviembre de 2018. Disponible en: https:// wWw.ambitojuridico.com/noticias/administrativo/administrativo-y-contrata cion/importante-corte-publica-sentencia-de

Asamblea Nacional Constituyente. Constitución Política de Colombia (1991). Bogotá; Editorial Unión Ltda.

Asociación Colombiana de Minería (ACM). (2018). Informe Desarrollo del Sector Minero Colombiano 2018-2022.

Carvajal, J. (2012). El sistema interamericano de derechos humanos: Democracia y derecho en Colombia. Bogotá, Colombia: Gran Colombia.

Carvajal, J., \& Guzmán, A. (2017). Economía de mercado y democracia: Elementos para una crítica al discurso del desarrollo promovido por las instituciones financieras internacionales. Justicia (31), 116-134.

Carvajal, J., \& Guzmán, A. (2017a). Las instituciones del sistema interamericano de protección a los derechos humanos: Un análisis de sus procedimientos y orientación estratégica. Revista Republicana (22), 183-207. 
Congreso de la República de Colombia. Ley 134 de 1994 «Por la cual se dictan normas sobre mecanismos de participación ciudadana», 31 de mayo de 1994. Diario Oficial nro. 41373

Congreso de la República de Colombia. Ley 136 de 1994 «Por la cual se dictan normas tendientes a modernizar la organización y el funcionamiento de los municipios». 2 de junio de 1994. Diario Oficial nro. 41377

Congreso de la República de Colombia. Ley 1757 de 2015 «Por la cual se dictan disposiciones en materia de promoción y protección del derecho a la participación democrática». 6 de julio de 2015. Diario Oficial nro. 49565.

Congreso de la República. Ley 685 de 2011. «Por la cual se expide el Código de Minas y se dictan otras disposiciones». 8 de agosto de 2001. Diario Oficial nro. 45273.

Corte Constitucional. Sentencia C-123/14. 5 de marzo de 2014. Magistrado Ponente: Alberto Rojas Ríos.

Corte Constitucional. Sentencia C-273/16. 25 de mayo de 2016. Magistrada Ponente: Gloria Stella Ortiz Delgado.

Corte Constitucional. Sentencia T-445/16. 19 de agosto de 2016. Magistrado Ponente: Jorge Iván Palacio.

Corte Constitucional. Sentencia SU095/18. 11 de octubre de 2018. Magistrada Ponente: Cristina Pardo Schlesinger.

El Espectador. (2018). «Los 9 municipios que le dijeron No a la minería usando la consulta popular», 10 de diciembre. Disponible en: https://sostenibilidad semana.com/medio-ambiente/articulo/los-9-municipios-que-le-dijeron-no-a-lamineria-usando-la-consulta-popular/41872

El Espectador. (2018). «Impunidad, el capítulo colombiano de los ambientalistas asesinados». 24 de julio. Disponible en: https://colombia2020.elespectador.com/ pais/impunidad-el-capitulo-colombiano-de-los-ambientalistas-asesinados

El Espectador. (2018). La minería se percibe como afectada por un 'cisma' llamado consultas populares, 30 de abril. Disponible en: https:/ / www.elespectador.com/economia/ mineria-afectada-por-un-cisma-llamado-consultas-populares-articulo-753093

Giraldo Gómez, J. (2018). Consultas populares mineras, ¿en qué quedó la autonomía territorial y la democracia participativa? Informe. Ámbito Jurídico, 19 de noviembre. Disponible en: https:/ / www.ambitojuridico.com/noticias/informe/administrativo-y-contratacion/consultas-populares-mineras-en-que-quedo-la 
Global Witness. (2017). «Defender la Tierra. Asesinatos globales de defensores/as de la tierra y el medio ambiente de 2016», p. 10. Disponible en: file:///C:/Users/ user/Downloads/Defender_la_tierra_-_Global_Witness_informe_sobre_ asesinatos_de_defensores_2017.pdf

Global Witness. (2018). «¿A qué precio? Negocios irresponsables y el asesinato de personas defensoras de la tierra y el medio ambiente en 2017».

Grupo Semillas. (2017). «Consultas populares, descentralización y modelo extractivo en Colombia», 2 de noviembre. Disponible en: http:/ / www.semillas.org.co/es/ consultas-populares-descentralizacin-y-modelo-extractivo-en-colombia

Martínez, M. (2018). Repertorios de la acción social colectiva frente al extractivismo minero en América Latina. Andamios, 15 (37), 43-73.

Montenegro, L. (2017). «Participación comunitaria en la protección del territorio. De las consultas populares a la toma de decisiones comunitarias». Revista Semillas No. 69/70 - Diciembre de 2017, pp. 61-65.

OCMAL, Observatorio de Conflictos Mineros de América Latina. (2017). Conflictos mineros en América Latina: extracción, saqueo y agresión, estado de la situación 2016. Perú: OCMAL.

Pisarrelo, G. (2001). Del Estado social legislativo al estado constitucional: Una protección de los derechos sociales. Isonomía. Revista de teoría y filosofía del derecho , 81-98.

Registraduría Nacional del Estado Civil. Comunicado de prensa nro. 528 de 2013 «Consulta popular de piedra, Tolima». Disponible: https:/ /www.registraduria. gov.co/En-consulta-popular-celebrada-hoy,10769.html

Registraduría Nacional de Estado Civil. Comunicado de prensa nro. 0021 de 2017. Disponible en: https://www.registraduria.gov.co/Habitantes-de-CabreraCundinamarca.html

Rodríguez, G., Frasser J., \& Andapiña D. (2017). Desarrollo sostenible, modelo extractivista e inversión extranjera en Colombia. Revista de Economía del Caribe nro. 19. Disponible en: http:/ / rcientificas.uninorte.edu.co/index.php/economia/ article/view/9599/html_384

Santos, B. (2013). La Caída del Angelus Novus. Bogotá, Colombia: ILSA.

Santos, B., \& Exeni, J. \&. (2012). Justicia indígena, plurinacionalidad e interculuralidad en Bolivia. Paz, Bolivia: Abya-Yala; Fundación Rosa Luxemburgo. 
Tierra Digna. (5 de septiembre de 2017). Áreas Estratégicas Mineras. Bogotá: Presentaciones y Relatorías - Jornadas sobre Transformaciones del Modelo Extractivo y Corporativo en Tiempos de Posacuerdo.

Tovar, C. (2017). «El factor moral en las consultas populares antimineras». Disponible en: https:/ / www.paisminero.com/component/k2/item/283-el-ordenamiento-minero-energetico-un-problema-moral 